\title{
REMODELLING OF ANGULAR DEFORMITY AFTER FEMORAL SHAFT FRACTURES IN CHILDREN
}

\author{
MURRAY E. WALLACE, EDUARD B. HOFFMAN
}

\section{From the Red Cross Children's Hospital, Cape Town}

\begin{abstract}
We reviewed 28 children with unilateral middle-third fractures of the femoral shaft who had an angular deformity after union of $10^{\circ}$ to $26^{\circ}$. At an average follow-up of 45 months (20 to 66), we measured remodelling of the proximal physis, the distal physis and the femoral shaft.

The average correction was $85 \%$ of the initial deformity. We found that $74 \%$ of correction occurred at the physes and only $26 \%$ at the fracture site. Neither the direction nor the magnitude of the angulation much influenced the degree of remodelling. Younger children remodelled only a little better than older children.

We conclude that in children under 13 years of age, malunion of as much as $25^{\circ}$ in any plane will remodel enough to give normal alignment of the joint surfaces.
\end{abstract}

Overgrowth after the conservative management of fractures of the femoral shaft in children has been clearly defined (Viljanto, Kiviluoto and Paananen 1975; Reynolds 1981; Clement and Colton 1986; Malkawi, Shannak and Hadidi 1986), and it has also been reported that rotational deformities can remodel (Brouwer, Molenaar and van Linge 1981; Hägglund, Hansson and Norman 1983). The importance of angular deformity after fracture is less clear although it has been reported in as many as $40 \%$ of cases (Malkawi et al 1986). Opinions vary on the potential for remodelling in regard to both the degree and the plane of the angulation.

Neer and Cadman (1957) and Griffin, Anderson and Green (1972) suggested that a $20^{\circ}$ angulation would remodel in any plane, while Barfod and Christensen (1958) considered that $25^{\circ}$ was acceptable. Other authors thought that varus and valgus deformities corrected poorly (Blount 1954; Dameron and Thompson 1959; Viljanto et al 1975), and that, in accordance with Wolff's law, remodelling was maximal in the plane of joint motion. Irani, Nicholson and Chung (1976) considered that $30^{\circ}$ of anterior and $15^{\circ}$ of medial angulation were acceptable, and Malkawi et al (1986) suggested that

M. E. Wallace, FCS SA(Orth), Registrar

Department of Orthopaedics, University of Cape Town

E. B. Hoffman, FCS SA(Orth), Consultant Orthopaedic Surgeon, University of Cape Town

Red Cross Children's Hospital, Klipfontein Road, Rondebosch, Cape Town, Republic of South Africa.

Correspondence should be sent to Dr E. B. Hoffman at 7 Marne Avenue, Newlands 7700, Republic of South Africa.

(C) 1992 British Editorial Society of Bone and Joint Surgery $0301-620 \mathrm{X} / 92 / 5380 \$ 2.00$

J Bone Joint Surg [Br] 1992; 74-B :765-9. initial angular deformities of up to $20^{\circ}$ in the coronal plane and $30^{\circ}$ in the sagittal plane would remodel into satisfactory alignment.

In all these reports only the changes at the fracture site were assessed; growth changes occurring at the physes during remodelling were not taken into consideration. In 1975, Pauwels postulated that the physis responds to malalignment by differential growth which tends to realign the shaft perpendicular to the major joint reaction forces (Ogden 1991). This physeal contribution to remodelling has been confirmed experimentally by Ryöppy and Karaharju (1974), Karaharju, Ryöppy and Mäkinen (1976) and Abraham (1989).

We have studied this physeal response to angular deformity in a series of clinical cases.

\section{PATIENTS AND METHODS}

We retrospectively reviewed 341 cases of unilateral fracture of the femoral shaft in children treated at the Red Cross Children's Hospital from June 1984 to November 1988. Of these, 70 had angulation of $10^{\circ}$ or more at the fracture site after union and we were able to make detailed studies of 28 of them at an average period of 45 months after fracture (20 to 66). There were 11 female and 17 male patients with an average age of 6.3 years ( 3 to 12). All the fractures involved the middle third of the shaft, and the major direction of tilt of the distal fragment was varus in 13, valgus in two, anterior in five, and posterior in eight.

Clinical disability and abnormality of alignment were assessed and full-length anteroposterior and lateral radiographs were taken of both femurs in each patient. We did not measure rotational deformity at initial union, 
but assessed this clinically, not radiographically, at follow-up. The patient was examined prone with the hip extended; no patient had a difference in range of rotation of more than $15^{\circ}$ between the two sides.

On the radiographs we measured the residual angle at the fracture site, and also the interphyseal angle in the coronal and sagittal planes. The latter was recorded as the angle between a line through the proximal physis and one through the distal physis (Fig. 1), measured for both femurs in each case. At the time of union the difference in physeal tilt between the fractured and normal femurs was equivalent to the angulation at the fracture site, but during growth, the physeal lines of the fractured femur tended to regain their former orientation. Where the

The interphyseal angle $(\chi)$ is measured at the intersection of the lines extended from proximal and distal physes.

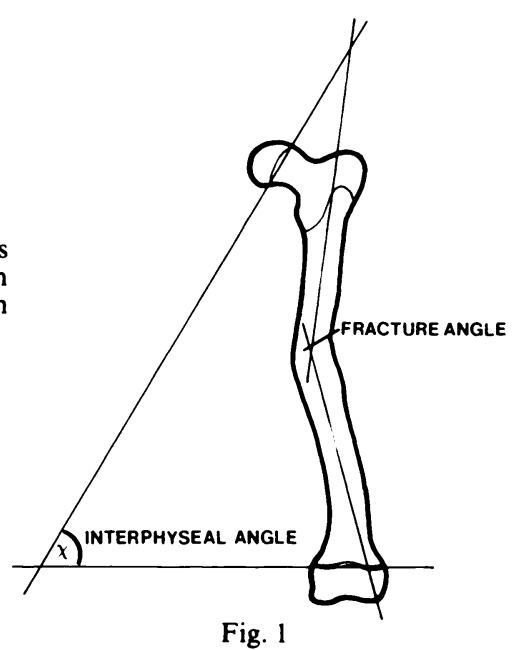

interphyseal angle had become the same in both femurs at follow-up it was considered that complete remodelling and joint realignment had taken place, so that the joint surfaces were again directed normally. Any residual difference in the interphyseal angle represented residual angular deformity. The contribution of the proximal and distal physes was determined by extending the lines drawn through the residual angle at the old fracture site to the physes and using trigonometric formulae.
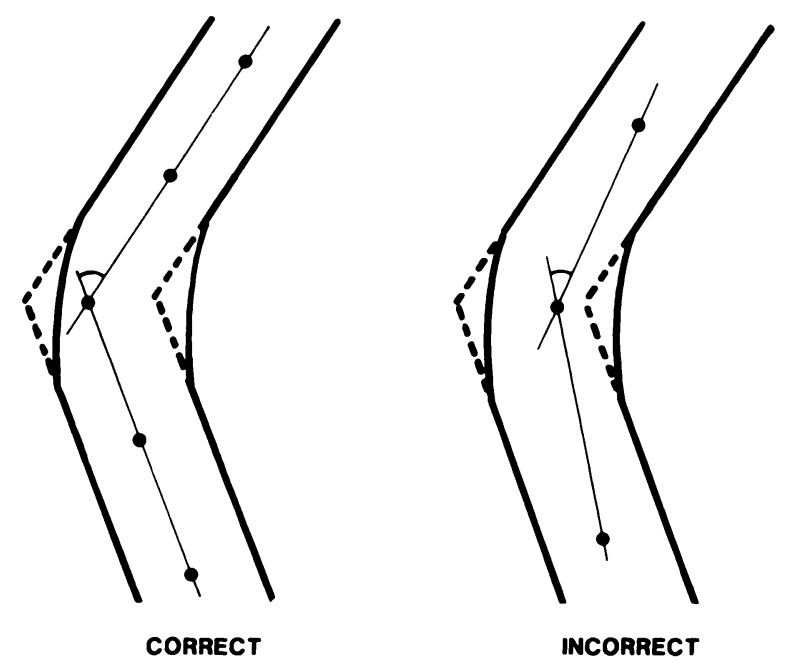

Fig. 2

The fracture-site angle on follow-up radiographs is measured between lines drawn on the unaffected shaft about $3 \mathrm{~cm}$ on either side of the fracture itself. Local remodelling can give a false impression of the correction of angulation.

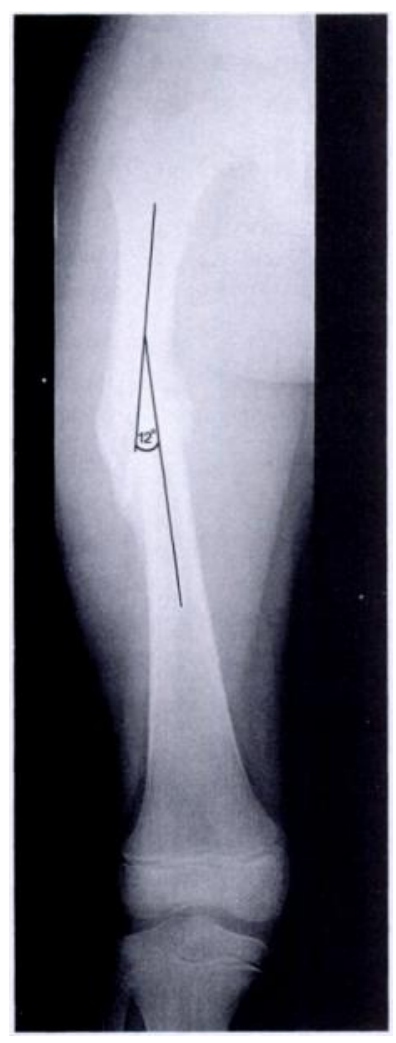

Fig. 3a

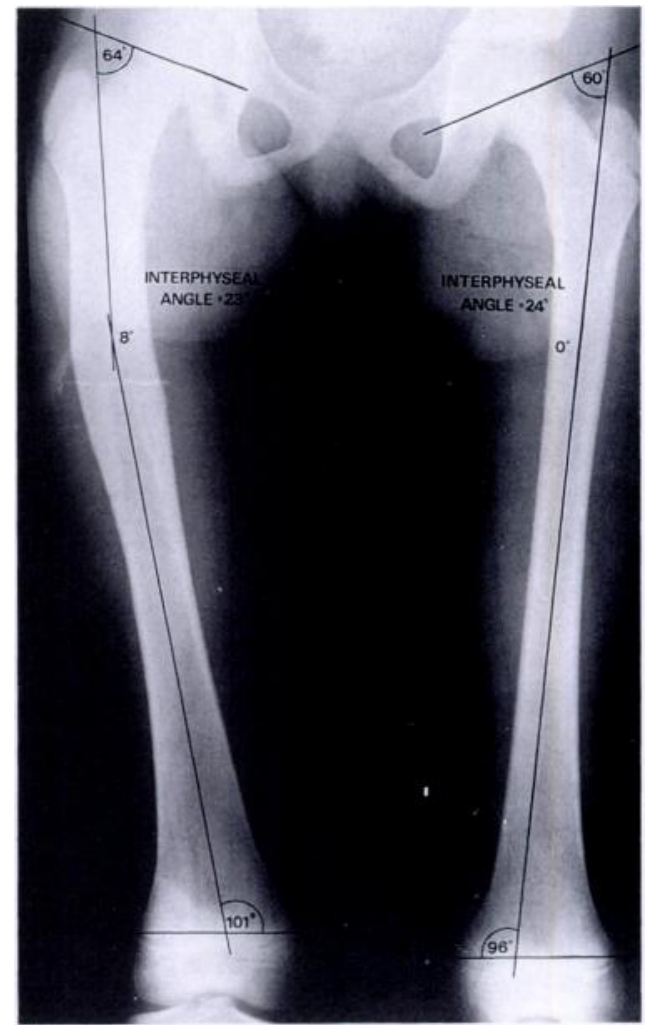

Fig. 3b
Figure 3a - An anteroposterior radiograph of the femur of a seven-year-old child showing a $12^{\circ}$ varus tilt at union. Figure $3 \mathrm{~b}-$ Remodelling at 4.5 years after fracture shows a residual fracture-site angle of $8^{\circ}$. The difference in interphyseal angles has improved from $12^{\circ}$ to $1^{\circ}$, however, implying an $11^{\circ}$ correction by differential physeal growth. 


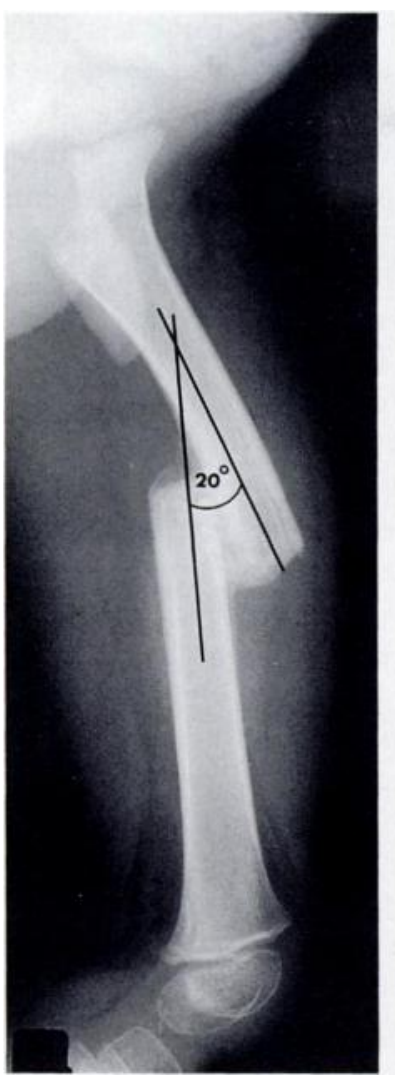

Fig. 4a

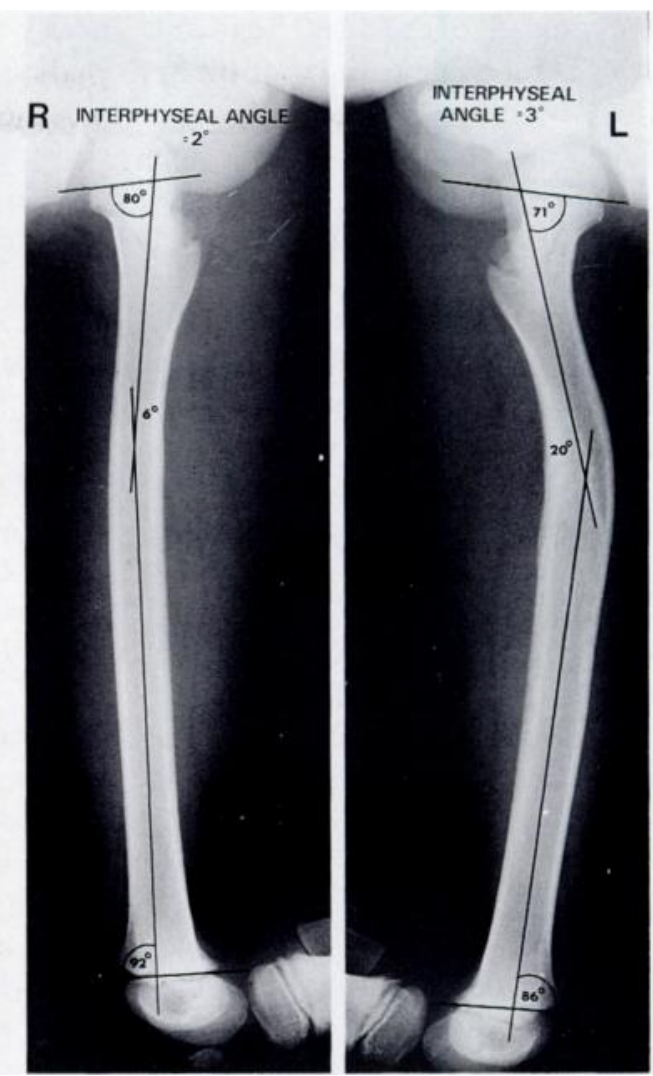

Fig. 4b

Figure $4 \mathrm{a}$ - A lateral radiograph of a five-year-old child with a $20^{\circ}$ posterior tilt at union. Figure $4 \mathrm{~b}$ - After four years there is no change in the fracture-site angle, but the difference in interphyseal angles has improved from $20^{\circ}$ to $1^{\circ}$.
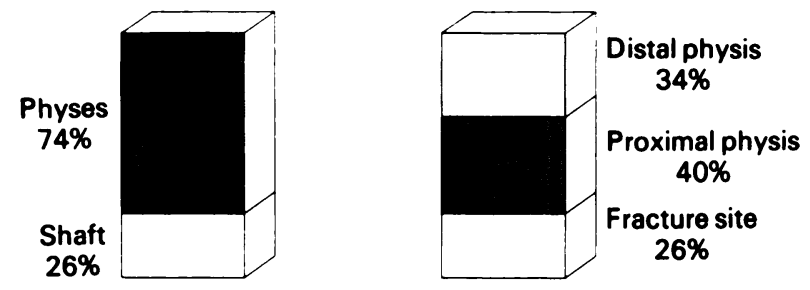

Fig. 5

The relative contributions of the physes and the shaft to correction of angulation.

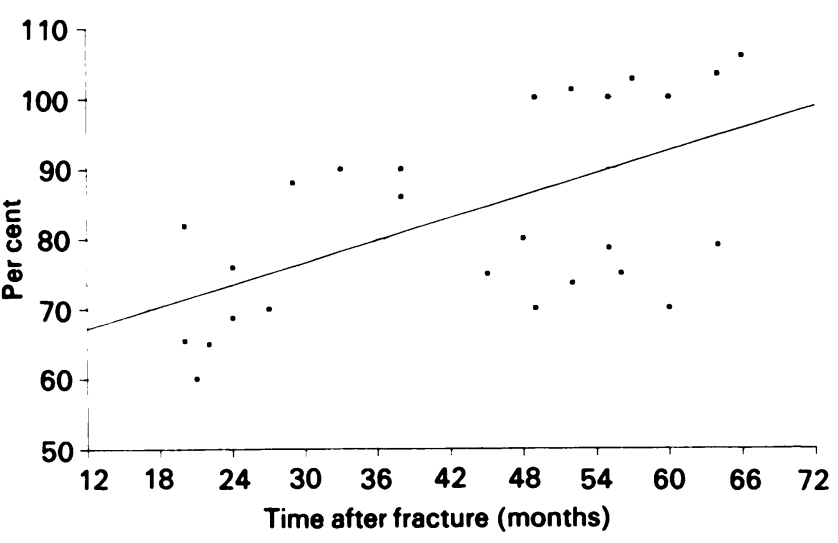

Fig. 6

The percentage correction of angulation related to time.
The measurement of the angle at a fracture site is shown in Figure 2. Local remodelling results in new bone deposition on the concave side and resorption on the convex side. This rounding-off at the fracture site could be misinterpreted as remodelling of the angular deformity. To avoid this error we drew the axis of the relatively unaffected shaft 2 to $3 \mathrm{~cm}$ on either side of the fracture and recorded the angle of intersection of these lines, as shown in Figures 3 and 4.

\section{RESULTS}

The average value of the main angulation in either plane at the time of union was $13.3^{\circ}$ (10 to 26). At follow-up an average of $85 \%$ of the interphyseal angulation had been corrected. We studied various features of this remodelling process.

Site. Of the correction of angulation, $74 \%$ had occurred at the physes and only $26 \%$ at the fracture site. Of the physeal remodelling, $53 \%$ was at the proximal and $47 \%$ at the distal physis (Fig. 5).

In seven femurs there had been no discernible change in angulation at the fracture site but almost full realignment of the physes. This finding may account for reports of complete lack of remodelling from studies in which only fracture-site angulation was measured at follow-up. 
Direction. We found that varus tilt of the distal fragment had corrected by $77 \%$, valgus tilt by $88 \%$, anterior tilt by $79 \%$ and posterior tilt by $90 \%$. These differences were discounted because of the small numbers and varying duration of follow-up in some groups.

Rate and duration. The amount of remodelling was related to the time from fracture, but with a fairly wide scatter of results (Fig. 6). On average $75 \%$ of the deformity had remodelled by three years. At five years, remodelling was virtually complete although in three patients there was only $70 \%$ correction. In three patients there was overcorrection by $5 \%$.

Age. We found only marginally better remodelling in younger children; the rate of remodelling was much the same.

Degree of angulation. The size of the initial angulation appeared to have some influence on remodelling: greater degrees of malunion tended to correct more fully. The rate of remodelling was the same, however, regardless of the original angle.

\section{DISCUSSION}

The basic mechanism which corrects angular deformities in growing long bones is not well understood. Remodelling at the fracture site accords with Wolff's law: new bone is laid down on the compression or concave side of the long bone, and the traditional understanding of this has been that it is maximal in the plane of joint movement and when the fracture is close to the end of the bone. The differential growth response of a physis under unequal loading has been described as the Hueter-Volkmann law (Ogden 1991).

Experimental studies showed that $50 \%$ of the remodelling of angulated fractures in dog tibiae occurred by differential physeal growth (Karaharju et al 1976). Abraham (1989) demonstrated in baboon forearms and tibiae that $33 \%$ to $47 \%$ of growth correction took place at the physes and $25 \%$ to $45 \%$ at the fracture site. Our method of calculating the interphyseal angle is similar to that for the growth-plate angle described by Abraham, but we differ in our measurement of the fracture-site angle (see Fig. 2). In a clinical setting, we found that $75 \%$ of the remodelling of femoral shaft fractures occurred at the physes.

We also observed that remodelling took place equally well in both the sagittal and the coronal planes. In the 13 patients with varus tilt, the largest group, $77 \%$ of the initial deformity was corrected. This is in contrast with varus and valgus deformities at the elbow which notoriously do not remodel. Part of the explanation may be the greater contribution made to growth by the lower femoral physis compared with that of the distal humeral physis.

It has been reported that remodelling may continue for more than five years after a fracture (Viljanto et al 1975; Malkawi et al 1986). Our Figure 6 shows that nearly $100 \%$ of the remodelling took place in the first six years. This difference may be because these authors measured only the fracture angle and not the interphyseal angle, and therefore underestimated the changes.

In our series, the younger children remodelled at the same rate but marginally better $(90 \%)$ than older children $(80 \%)$. This is at variance with the findings of Viljanto et al (1975) and Malkawi et al (1986). The largest angulation that we studied was $26^{\circ}$, and there may be a limit beyond which full correction is impossible. Remodelling of an angle of $35^{\circ}$ was reported by Karaharju et al (1976).

We did not study rotational remodelling, and it can be argued that unmeasured rotation may have influenced our interpretation of changes in angular deformities. We do not believe, however, that rotation played a significant role. We did not measure rotation at fracture union, but found that the radiological angular deformity at fracture union was always maximal in one plane: either varus, valgus, anterior or posterior tilt. Hägglund et al (1983) showed that at initial union after treatment by skin traction, rotational deformity never exceeded $20^{\circ}$. Our patients were all treated either by skin traction in a Thomas splint or immediate spica application and in a separate study of 50 patients treated by an immediate spica we confirmed that no patient at union had a difference in rotation of over $20^{\circ}$. Our clinical finding at follow-up of a difference of rotation between the two sides of less than $15^{\circ}$ is within the normal physiological range (Brouwer et al 1981).

Each year, we treat approximately 200 children under 12 years of age with fractured femoral shafts, using early spica application for about 100 between the ages of two and ten years. Of these $15 \%$ unite with angulation of $10^{\circ}$ or more, and our study has reassured us that up to $25^{\circ}$ of angulation in children of 12 years or younger will remodel satisfactorily.

The authors would like to thank Mrs $\mathrm{V}$. Barrow for typing the
manuscript and $\mathrm{Mr} \mathrm{M}$. Wyeth for preparing the illustrations.
No benefits in any form have been received or will be received
from a commercial party related directly or indirectly to the subject of this article.

\section{REFERENCES}

Abraham E. Remodeling potential of long bones following angular osteotomies. J Pediatr Orthop 1989; 9:37-43.

Barfod B, Christensen J. Fractures of the femoral shaft in children with special reference to subsequent overgrowth. Acta Chir Scand 19589; 116:235-50.

Blount WP. Fractures in children. Baltimore: Williams \& Wilkins, 1954.

Brouwer KJ, Molenaar JC, van Linge B. Rotational deformities after femoral shaft fractures in childhood: a retrospective study 27-32 years after the accident. Acta Orthop Scand 1981; 52:81-9.

Clement DA, Colton CL. Overgrowth of the femur after fracture in childhood: an increased effect in boys. J Bone Joint Surg [Br] 1986; 68-B:534-6.

Dameron TB, Thompson HA. Femoral shaft fractures in children: treatment by closed reduction and double spica cast immobilisation. J Bone Joint Surg [Am] 1959; 41-A:1201-12. 
Griffin PP, Anderson M, Green WT. Fractures of the shaft of the femur in children: treatment and results. Orthop Clin North Am 1972; 3:213-24.

Hägglund G, Hansson LI, Norman O. Correction by growth of rotationa deformity after femoral fracture in children. Acta Orthop Scand $1983 ; 54: 858-61$.

Irani RN, Nicholson JT, Chung SMK. Long-term results in the treatment of femoral-shaft fractures in young children by immediate spica immobilization. J Bone Joint Surg [ Am] 1976; 58-A :945-51.

Karaharju EO, Ryöppy SA, Mäkinen RJ. Remodelling by asymmetrical epiphyseal growth: an experimental study in dogs. J Bone Joint Surg $[B r] 1976 ; 58-B: 122-6$.

Malkawi H, Shannak A, Hadidi S. Remodelling after femoral shaft fractures in children treated by the modified Blount method. $J$ Pediatr Orthop 1986; 6:421-9.
Neer CS II, Cadman EF. Treatment of fractures of the femoral shaft in children. JAMA 1957; 162:634-7.

Ogden JA. The uniqueness of growing bones. In: Rockwood CA Jr, Wilkins KE, King RE, eds. Fractures in children. Third ed. New York, etc: JB Lippincott, 1991 :1-86.

Pauwels F. Eine Klinische Beubachtung als beispiel und beweis für funktionelle Anpassung des Knochens durch Langenwachstum. $Z$ Orthop 1975; 113:1-5.

Reynolds DA. Growth changes in fractured long-bones: a study of 126 children. J Bone Joint Surg [ Br] 1981 ; 63-B:83-8.

Ryöppy S, Karaharju EO. Alteration of epiphyseal growth by an experimentally produced angular deformity. Acta Orthop Scand $1974 ; 45: 490-8$.

Viljanto J, Kiviluoto H, Paananen M. Remodelling after femoral shaft fracture in children. Acta Chir Scand $1975 ; 141: 360-5$. 